\title{
Producción de hidrógeno usando la fracción cetónica de bio-oil en un reactor de lecho fijo
}

\author{
Pilar Tarifa, Jorge Plou, Paul Durán, Javier Herguido, José Ángel Peña \\ Grupo de Catálisis, Separaciones Moleculares e Ingeniería del Reactor (CREG) \\ Instituto de Investigación en Ingeniería de Aragón (I3A). \\ Universidad de Zaragoza, Mariano Esquillor s/n, 50018, Zaragoza, Spain. \\ Tel. +34-976762707, Fax +34-976762043, e-mail: pauduran@unizar.es
}

\begin{abstract}
Para la obtención y purificación de hidrógeno se han simultáneado los procesos de descomposición catalítica y steam-iron en un mismo reactor. En este trabajo se ha ensayado el comportamiento de la fracción cetónica de un bio-oil para la obtención de hidrógeno de alta pureza. Los compuestos utilizados han sido la acetona y la hidroxiacetona.
\end{abstract}

\section{Introducción}

El hidrógeno en un fuerte candidato para reemplazar la dependencia energética de los combustibles fósiles porque es una fuente limpia y renovable. El uso de biomasa y en particular bio-oils, puede ser una interesante alternativa. Estos son los productos líquidos que provienen de la pirolisis rápida de biomasa. Son materiales de bajo coste constituidos por materiales orgánicos oxigenados y cuya composición depende de la materia prima utilizada y de las condiciones del proceso de producción.

Este trábajo analiza el comportamiento de la fracción cetónica de un bio-oil en la producción de hidrógeno mediante el proceso steam-iron (Messerschmidt 1910). Esta fracción puede llegar a constituir un $17 \%$ (base seca) del total del combustible (Bertero et al. 2012). Como compuestos modelo se han elegido la hidroxiacetona y la acetona. En estudios previos, se examinó el comportamiento de las fracciones ácidas (ácido acético) y las alcoholicas (metanol y etanol) (Campo et al. 2013; Hormilleja et al. 2014). En la primera etapa del proceso, el óxido de hierro es reducido por los productos generados en la descomposición catalítica del bio-oil, constituyendo una corriente rica en hidrógeno y monóxido de carbono (altamente reductora). En la siguiente etapa, el sólido previamente reducido, es reoxidado con vapor de agua generando hidrógeno de alta pureza con calidad suficiente para ser introducido en una pila de combustible PEMFC.
Los experimentos se han llevado a cabo en un reactor de lecho fijo de cuarzo (diámetro interno 13mm, 2,5 g de sólido). En la etapa de reducción se han alimentado hidroxiacetona y/o acetona (presiones parciales de 0.05 a 0.15 bar) diluidas con helio. La temperatura de trabajo ha variado de 600 a $800{ }^{\circ} \mathrm{C}$. Las oxidaciones se llevaron a cabo siempre a $500{ }^{\circ} \mathrm{C}$, temperatura óptima para la generación de hidrógeno libre de $\mathrm{CO}$ y $\mathrm{CO}_{2}$. El sólido, sintetizado en laboratorio, consta de una mezcla mecánica de dos componentes: por un lado óxido de hierro dopado con cerio y aluminio y por otro lado un aluminato de níquel no estequiométrico con exceso de níquel. Los gases se analizaron mediante un cromatógrafo de gases y un espectrómetro de masas operando en paralelo.

\section{Resultados}

En la etapa de reducción, se ha observado la descomposición total de las cetonas en todas las condiciones de operación (catalítica). La corriente de gases está compuesta principalmente por $\mathrm{H}_{2}$ y $\mathrm{CO}$, que actúan sobre el sólido reduciéndolo y generando $\mathrm{CO}_{2}$ y $\mathrm{H}_{2} \mathrm{O}$ (Figura 1). Cuando la hidroxiacetona es el único reactivo, se observan pequeñas cantidades de metano. No se han observado otro tipo de compuestos. La deposición de coque es mayor a las temperaturas bajas en el rango estudiado $\left(600{ }^{\circ} \mathrm{C}\right)$, aunque éste permanece inerte durante la etapa de oxidación en la que se obtiene hidrógeno puro. El sólido fue oxidado completamente hasta magnetita $\left(\mathrm{Fe}_{3} \mathrm{O}_{4}\right)$ y no muestra fatiga térmica incluso a altas temperaturas $\left(800^{\circ} \mathrm{C}\right)$.

\section{REFERENCIAS}

[1]. BERTERO, M., PUENTE, G. de la and SEDRAN, U. Fuels from bio-oils: Bio-oil production from different residual sources, characterization and thermal conditioning. Fuel. 2012, 95, 263-271. Available from: doi:10.1016/j.fuel.2011.08.041

[2]. CAMPO, R., DURÁN, P. PLOU, J., HERGUIDO, J. and PEÑA, J.A. Combined production and 
purification of hydrogen from methanol using steam iron process in fixed bed reactor. Journal of Power Sources. 2013, 242, 520-526. Available from: doi:10.1016/j.jpowsour.2013.05.146

[3]. HORMILlEJA, E., DURÁN, P., PLOU, J., HERGUIDO, J. and PEÑA, J.A. Hydrogen from ethanol by steam iron process in fixed bed reactor. International Journal of Hydrogen Energy. 2014, 39(10), 5267-5273. Available from: doi:10.1016/j.ijhydene.2014.01.002

[4]. MESSERSCHMITT, A. Process of producing hydrogen. U.S., Patent No. 465,686 ed. 1910

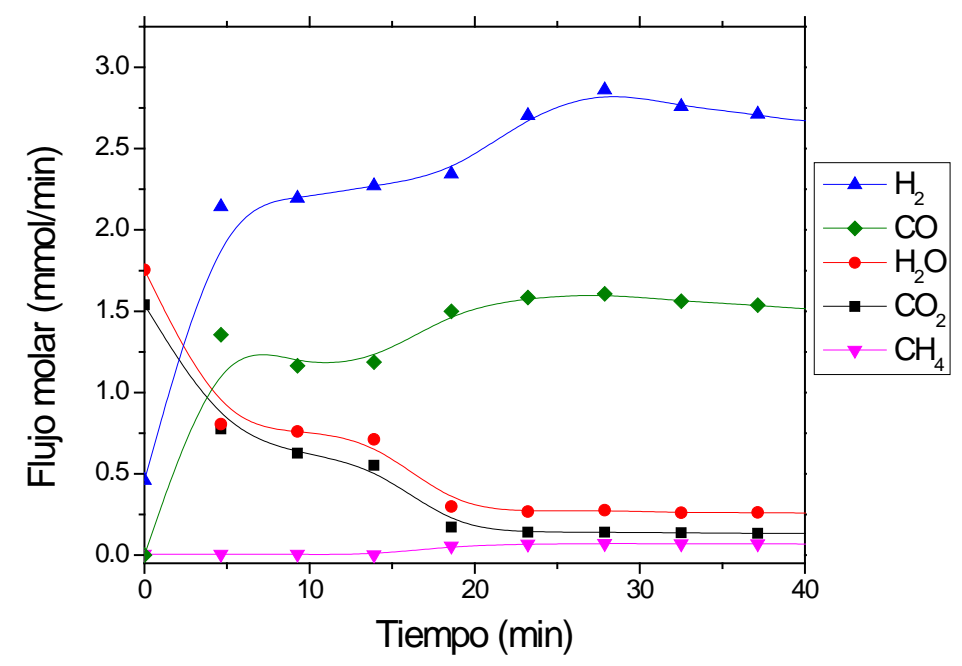

Figura 1. Productos de la reducción con hidroxiacetona a $700^{\circ} \mathrm{C}$ 